\title{
Mushroom toxicity in academic literature: Holistic analysis of the global publications on mushroom poisoning between 1975 and 2019
}

\author{
Özgür Yağan ${ }^{1}$, Engin Şenel${ }^{2}$, Selçuk Kayır ${ }^{1}$ \\ ${ }^{1}$ Department of Anesthesiology, School of Medicine, Hitit University, Çorum, Turkey \\ ${ }^{2}$ Department of Dermatology, School of Medicine, Hitit University, Çorum, Turkey
}

Received: 2020-07-21.

Accepted: 2020-09-06

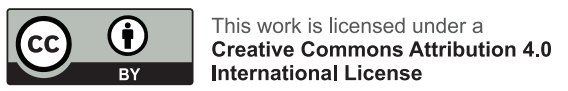

J Clin Med Kaz 2020; 6(60):48-52

Corresponding author:

Özgür Yağan.

E-mail: ozguryagan@hotmail.com;

ORCID: https://orcid.org/0000-0003-1596-1421

\section{Abstract}

Background and objective: Mushroom poisoning is one of the global public health problems. In our study, we aimed to analyze bibliometric and scientometric analysis of mushroom poisoning between 1975 and 2019.

Methods: All data used in the present study were retrieved from Web of Science databases titled Web of Science Core Collection, Russian Science Citation Index, SciELO Citation Index and Korean Journal Database.

Results: A total of 3508 documents were yielded from our preliminary WoS database search. The most productive year was 2018 with 239 documents. The most common documents types were original article, case report, reviews and meeting abstract. United States of America (USA) was the leading country with 667 documents followed by China, Japan and France. All countries in top ten contributor countries' list were developed but only Turkey and Poland were developing according to UN criteria. Publications were produced from nearly all regions of the world except for some countries in Africa. Chinese University of Hong Kong (China) was the most contributor institution with 80 documents. Clinical Toxicology was detected to be the most productive source title. Total number of citations was 62,452 times and an average citation per item was 17.8 times. Citations increased gradually, and the peak year was 2019 with 6034 citations.

Conclusion: Findings of our study could help the experts in the fields of toxicology, intensive care and emergency medicine to identify the global research trends and patterns of mushroom toxicity and to offer a basis for future research directions.

Key words: mushroom, mushroom poison, mushroom poisoning, mycetism, bibliometrics, scientometrics, publication trend analysis

\section{Introduction}

Mushroom poisoning is one of the global health problems. It is estimated there are more than 5000 mushroom species worldwide. Only $20-25 \%$ of mushrooms have been named and $3 \%$ of these are poisonous [1,2].

Mushrooms are commonly consumed as food in some countries and regions, while they are treated suspiciously in other countries. Wild mushroom collecting is widespread in Europe (especially Slavic countries and Italy), America and the Far East. However, mushroom collection and consumption is rare in the UK $[3,4]$. "Mushrooming" is very popular in the USA. In most states, there are societies that organize mushroomhunting trips emphasizing correct identification and safety. (North American Mycological Association 2017)

It may be difficult to fully and correctly identify mushroom species. Significant morphological variations may occur in the same mushroom species linked to seasons, geographical location and the maturity of the mushroom. Most ingested mushrooms are non-toxic, or are only gastrointestinal irritants and cause mild to moderate degrees of toxic effects $[5,6]$. In the USA and Europe, nearly all deaths linked to mushroom intoxication belong to the Amanita species (A. phalloides, A.virosa, A. bisporigera) $[7,8]$. 
Ignoring the deliberate consumption of psychoactive mushrooms, the majority of mushroom poisonings are unintended and caused by misidentification of species. Mushroom intoxications due to suicide attempts or criminal actions are very rare events $[9,10]$. The amount of toxicity varies linked to the age of the mushroom, season, geographical location and the preparation of the mushroom. While one person consuming the same mushroom may show toxicity symptoms, another person may be asymptomatic [7].

A variety of signs and symptoms like gastroenteritis, central nervous system (CNS) disorders and liver failure may occur linked to the toxin contained in poisonous mushrooms $[4,11,12]$. Though gastroenteritis and CNS disorders are generally temporary, liver failure may be irreversible and deadly without transplantation.

Poisoning due to mushrooms causing gastrointestinal irritation may have mild or moderate degrees of clinical progress, so the majority of these cases are not reported in the literature. However, as gastrointestinal symptoms may occur after intoxication with mushrooms containing amatoxin, it is important to differentiate benign gastroenteritis from lifethreatening amatoxin intoxication $[13,14]$.

Bibliometrics is a popular statistical branch to analyze a certain field in the scientific literature by investigating publication trend, contributions of authors, institutions and countries and expectations in academic future [15]. Although there has been an increasing popularity of bibliometric and scientometric researches, to the best of our knowledge this is the first study to analyze literature related to mushroom poisoning.

The first written record of mushroom poisoning is a poem written in the 5 th century BC by the Greek poet Euripides about the deaths of a mother and 3 children after eating mushrooms [16]. In our study we aimed to perform bibliometric and scientometric analyses of publications related to mushroom intoxication from 1975 to 2019. This study analyzed the quantitative (global publications output) and qualitative (citation analysis) measures.

\section{Material and methods}

All data used in the present study were retrieved from Web of Science databases (WoS) (Thomson Reuters, New York, NY, USA) titled Web of Science Core Collection, Russian Science Citation Index, SciELO Citation Index and Korean Journal Database. We included all materials published between 1975 and 2019. In our search we used the keywords of "mushroom poisoning", "mushroom toxicity", "mushroom poisonous", "mushroom poison", "mushroom intoxication" and "mycetism". We generated an info-map to clarify global productivity in this field by using GunnMap source and info-graphics to create bibliometric connection networks by using VosViewer software $[17,18]$.

\section{Results \\ General features of the literature}

A total of 3508documents were yielded from our preliminary WoS database search. English was the primary language of the literature $(93.13 \%)$ followed by German, French, Spanish and Korean (3.44, 2.30, 1.65 and 1.39, respectively). The most productive year was 2018 with 239 documents (Figure 1). The most common documents types were original article, case report, reviews and meeting abstract $(n=3097,338,304$ and 303 items, respectively; Table 1). The most searched areas in this field were detected to be toxicology, pharmacology, biochemistry, and microbiology $(71.57,49.45,49.23$ and $44.18 \%$, respectively; Table 2).
Figure 1 - Published documents each year in research field

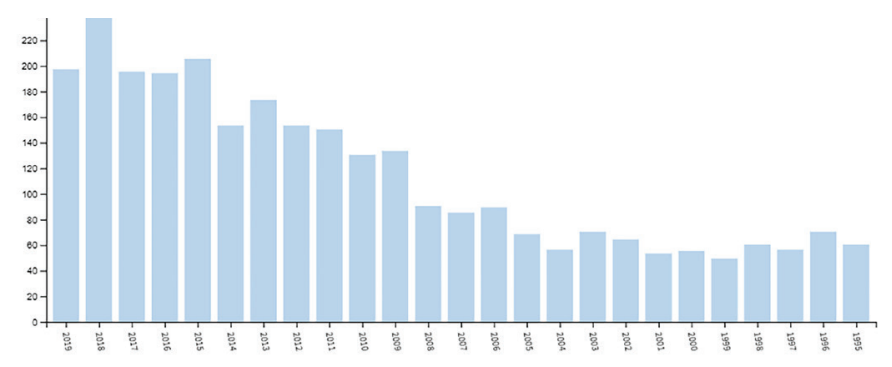

Table 1

Document types in scientific literature related to mushroom poisoning published between 1975 and 2019.

\begin{tabular}{|l|l|l|}
\hline Document Type & Numbera & \%a \\
\hline Article & 3097 & 88.28 \\
\hline Case Report & 338 & 9.63 \\
\hline Review & 304 & 8.66 \\
\hline Abstract & 303 & 8.63 \\
\hline Meeting & 270 & 7.69 \\
\hline Letter & 154 & 4.39 \\
\hline Editorial & 54 & 1.53 \\
\hline Book & 38 & 1.08 \\
\hline Clinical Trial & 18 & 0.51 \\
\hline Unspecified & 12 & 0.34 \\
\hline Early Access & 7 & 0.20 \\
\hline News & 6 & 0.17 \\
\hline Biography & 4 & 0.11 \\
\hline Correction & 4 & 0.11 \\
\hline Retracted Publication & & \\
\hline 1 & 0.02 & \\
\hline Other & 1021 & 29.10 \\
\hline Total & $\mathbf{3 5 0 8}$ & $\mathbf{1 0 0}$ \\
\hline
\end{tabular}

a Total number may exceed the number of the publications in this area and total percentages may exceed $100 \%$ since certain items were included in more than one category

Table 2

The first 10 research areas of the publications related to mushroom poisoning

\begin{tabular}{|l|l|l|}
\hline Research Areas & Number of publicationsa & \%a \\
\hline Toxicology & 2511 & 71.57 \\
\hline Pharmacology \& Pharmacy & 1735 & 49.45 \\
\hline Biochemistry & 1727 & 49.23 \\
\hline Microbiology & 1550 & 44.18 \\
\hline Mycology & 1523 & 43.41 \\
\hline Plant Sciences & 1392 & 39.68 \\
\hline Food Science Technology & 1002 & 28.56 \\
\hline Agriculture & 942 & 26.85 \\
\hline Chemistry & 865 & 24.65 \\
\hline $\begin{array}{l}\text { Environmental Sciences } \\
\text { Ecology }\end{array}$ & 715 & 20.38 \\
\hline
\end{tabular}

a Total number may exceed the number of the publications in this field and total percentages may exceed $100 \%$ because certain items were included in more than one category 


\section{Global productivity and performances of the countries}

As we investigated the contributions of the countries to the literature we noted that the United States of America (USA) was the leading country with 667 documents followed by China, Japan and France (n=327, 305 and 189 items, respectively, Figure 2). All countries in top ten contributor countries' list were developed but only Turkey and Poland were developing according to UN criteria [19]. Publications were produced from nearly all regions of the world except for some countries in Africa (Figure 3).

Figure $\mathbf{2}$ - Top ten contributor countries in productivity of literature

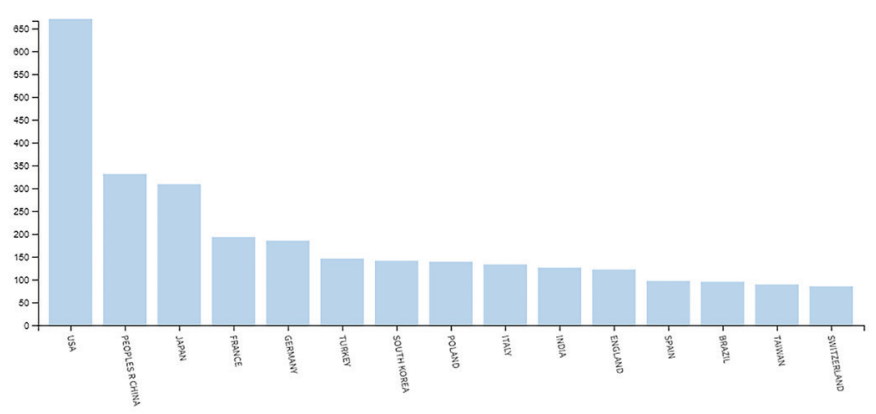

Figure 3 - Total publication density of world countries

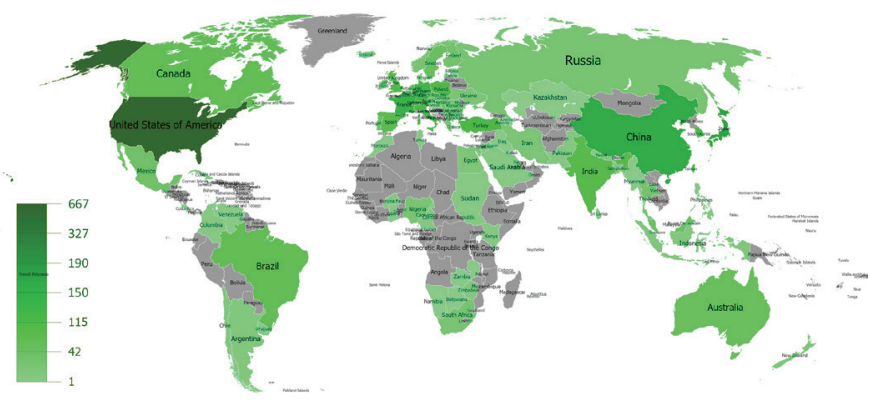

\section{Authors, institutions, journals and academic meetings}

Falandysz J, Ferreira ICFR and Kawagishi $\mathrm{H}$ were detected to be the most prolific authors in this field $(n=67,58$ and 40, respectively; Table 3). Chinese University of Hong Kong (China) was the most contributor institution with 80 documents followed by University of California (USA) and University Of Gdansk (Poland) ( $\mathrm{n}=78$ and 74 documents, respectively; Table 4).Clinical Toxicology was detected to be the most productive source title with 127 articles followed by International Journal of Medicinal Mushrooms and Food And Chemical Toxicology ( $n=96$ and 56 items, respectively; Table 5). We noted that the most contributor academic meeting was Annual Meeting of the North American Congress of Clinical Toxicology with 21 abstracts in this field.

\section{Citation analysis of the literature}

We measured $\mathrm{H}$-index of the literature as 99 . Total number of citations was 62,452 times and an average citation per item was 17.8 times. Citations increased gradually, and the peak year was 2019 with 6034 citations. A review titled "Mushrooms, tumors, and immunity" by Borchers, AT, Stern JS, et al. published in 1999 was the most cited article (369 times totally, Table 6).

\begin{tabular}{|l|l|l|}
\hline Author & Record Count & $\%$ \\
\hline Falandysz J & 67 & 1.91 \\
\hline Ferreira ICFR & 58 & 1.65 \\
\hline Kawagishi H & 40 & 1.14 \\
\hline Ng TB & 40 & 1,14 \\
\hline Toth B & 26 & 0.74 \\
\hline Shirahama H & 19 & 0.54 \\
\hline Zilker T & 17 & 0.48 \\
\hline Faulstich H & 16 & 0.45 \\
\hline Sabaratnam V & 16 & 0.45 \\
\hline Wieland T & 16 & 0.45 \\
\hline
\end{tabular}

*of total documents published in literature

\section{Table 4}

The top ten institutions by number of publications in literature related to mushroom poisoning

\begin{tabular}{|l|l|l|}
\hline Organizations & Document number & $\%$ \\
\hline $\begin{array}{l}\text { Chinese University Of Hong Kong } \\
\text { (China) }\end{array}$ & 80 & 2.28 \\
\hline $\begin{array}{l}\text { University Of California System } \\
\text { (USA) }\end{array}$ & 78 & 2.22 \\
\hline University Of Gdansk (Poland) & 74 & 2.11 \\
\hline $\begin{array}{l}\text { Chinese Academy Of Sciences } \\
\text { (China) }\end{array}$ & 51 & 1.45 \\
\hline $\begin{array}{l}\text { Centre National De La Recherche } \\
\text { Scientifique (France) }\end{array}$ & 42 & 1.19 \\
\hline University Malaya (Malaysia) & 40 & 1.14 \\
\hline Chinese Acad SCI (China) & 32 & 0.91 \\
\hline Max Planck Society (Germany) & 30 & 0.85 \\
\hline $\begin{array}{l}\text { University Of Nebraska System } \\
\text { (USA) }\end{array}$ & 30 & 0.85 \\
\hline Shizuoka University (Japan) & 29 & 0.82 \\
\hline
\end{tabular}

\section{Table 5}

The first 10 journal source according to the number of published documents in literature related to mushroom poisoning

\begin{tabular}{|l|l|l|}
\hline Journal Name & $\begin{array}{l}\text { Number of } \\
\text { Publications }\end{array}$ & $\%$ \\
\hline Clinical Toxicology & 127 & 3.60 \\
\hline $\begin{array}{l}\text { International Journal Of Medicinal } \\
\text { Mushrooms }\end{array}$ & 96 & 2.73 \\
\hline Food And Chemical Toxicology & 56 & 1.59 \\
\hline Toxicon & 56 & 1.59 \\
\hline Journal Of Agricultural And Food Chemistry & 38 & 1.08 \\
\hline Journal Of Ethnopharmacology & 34 & 0.69 \\
\hline Veterinary And Human Toxicology & 31 & 0.88 \\
\hline Clinical Toxicology Philadelphia & 28 & 0.79 \\
\hline Mycopathologia & 25 & 0.71 \\
\hline Plos One & 25 & 0.71 \\
\hline
\end{tabular}

\section{Bibliometric network analysis}

Detailed keyword analysis of the literature revealed the most used keywords such as "mushroom poisoning", "mushroom(s)", "toxicity", "poisoning" and "Amanita Phalloides". We created a bibliometric keyword network and we noticed a multi-branched pattern this keywords centered (Figure 4). We generated a cooperation network of the countries and found that the USA was the most collaborative country in the literature (Figure 5). 


\begin{tabular}{|c|c|c|c|c|c|}
\hline Article & Author(s) & Journal Name/ & & & \\
\hline Published & Year & Total Cita-tion & Average Citations per Year & & \\
\hline $\begin{array}{l}\text { Mushrooms, tumors, and } \\
\text { immunity }\end{array}$ & Borchers, AT; Stern, JS; et al. & $\begin{array}{l}\text { Proceedings Of The Society } \\
\text { For Experimental Biology And } \\
\text { Medicine }\end{array}$ & 1999 & 369 & 16.77 \\
\hline $\begin{array}{l}\text { Silymarin: A review of its } \\
\text { clinical properties in the } \\
\text { management of hepatic } \\
\text { disorders }\end{array}$ & Wellington, K; Jarvis, B & Biodrugs & 2001 & 345 & 17.25 \\
\hline $\begin{array}{l}\text { Treatment of amatoxin } \\
\text { poisoning: } 20 \text {-year } \\
\text { retrospective analysis }\end{array}$ & Enjalbert, F; Rapior, S; et al. & $\begin{array}{l}\text { Journal Of Toxicology-Clinical } \\
\text { Toxicology }\end{array}$ & 2002 & 239 & 12.58 \\
\hline Hepatotoxicity of botanicals & $\begin{array}{l}\text { Stickel, Felix; Egerer, Gerlinde; } \\
\text { et al. }\end{array}$ & Public Health Nutrition & 2000 & 173 & 8.24 \\
\hline $\begin{array}{l}\text { A mini-review of chemical } \\
\text { composition and nutritional } \\
\text { value of edible wild-grown } \\
\text { mushroom from China }\end{array}$ & Wang, Xue-Mei; Zhang, Ji; et al. & Food Chemistry & 2014 & 161 & 23.0 \\
\hline Cytotoxic fungi - an overview & Karlson-Stiber, C; Persson, H & Toxicon & 2003 & 157 & 8.72 \\
\hline Toxins of Amanita phalloides & Vetter, J & Toxicon & 1998 & 152 & 6.61 \\
\hline $\begin{array}{l}\text { Gene family encoding the } \\
\text { major toxins of lethal Amanita } \\
\text { mushrooms }\end{array}$ & $\begin{array}{l}\text { Hallen, Heather E.; Luo, Hong; } \\
\text { et al. }\end{array}$ & $\begin{array}{l}\text { Proceedings Of The National } \\
\text { Academy Of Sciences Of The } \\
\text { United States Of America }\end{array}$ & 2007 & 148 & 10.57 \\
\hline $\begin{array}{l}\text { Functional properties of edible } \\
\text { mushrooms }\end{array}$ & Chang, R & Nutrition Reviews & 1996 & 148 & 5.92 \\
\hline $\begin{array}{l}\text { Kinetics of amatoxins in } \\
\text { human poisoning - therapeutic } \\
\text { implications }\end{array}$ & Jaeger A; Jehl F; et al. & $\begin{array}{l}\text { Journal Of Toxicology-Clinical } \\
\text { Toxicology }\end{array}$ & 1993 & 123 & 4.39 \\
\hline
\end{tabular}

Figure 4 - Keyword network in research field

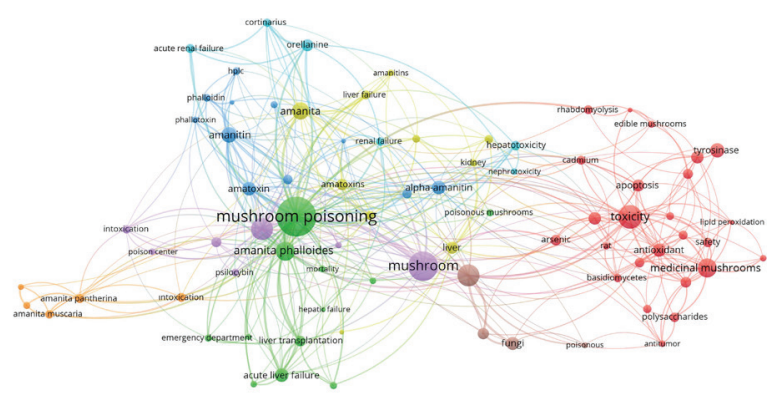

A vosviewer

\section{Discussion}

Since the first report that Pritzard proposed the term of "bibliometrics" there have been many bibliometric studies published in the literature [20]. Bibliometrics uses statistical and mathematical methods to measure contributions of researchers, foundations and countries to the literature. To the best of our knowledge, our study is the first bibliometric research in the field of mushroom toxicity.

There are many cases of mushroom poisoning reported each year from regions with excess mushroom consumption. The main causes of mushroom poisoning are insufficient information and misidentification of species. Some species contain dangerous toxins causing a variety of symptoms and syndromes. Not only poisonous mushrooms, some edible mushroom species may contain poisonous compounds. The severity of poisoning is linked to the amount consumed. Correct identification of mushrooms is the basic step to ensure the
Figure 5 - Collaborative country network in research field

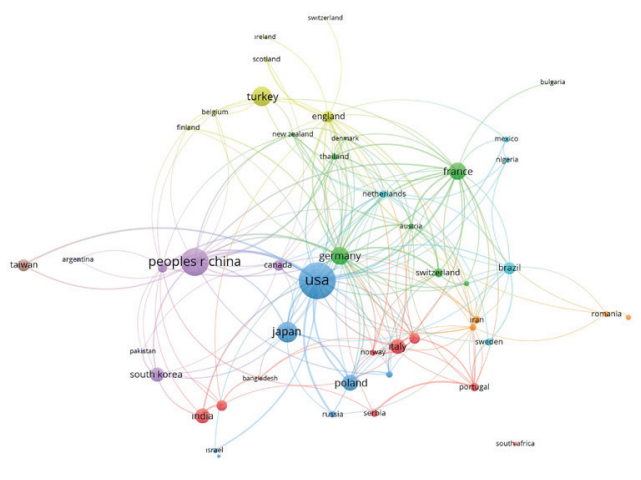

possibility of successful treatment by preventing poisoning and rapidly identifying poisoning symptoms.

It is important that people know that the toxins in most poisonous mushroom species are resistant to cooking, conserving, freezing and any other processing. As a result, the only way to prevent intoxication is to avoid consuming poisonous species. There is no international guideline for mushroom intoxication cases. Treatment is directed by clinical symptoms and there are no antidotes for the majority of mushroom toxins. Modern intensive care treatments have significantly reduced mushroom mortality and morbidity [21]. Diagnosis of mushroom intoxication should be based on accurate identification of the mushroom, clinical features and laboratory analyses [22].

Mortal mushroom intoxication cases have been reported previously. Additionally, the features of the toxins, syndromes and toxicity mechanisms have not been summarized. As a result, it is very important to review information about mushroom 
toxins and deaths. To identify the possible side effects of edible and medical mushrooms and to ensure safe consumption, experimental and clinical research is required.

Due to reasons such as the "return to nature" in recent years and increased demand for organic food, it is stated there may be an increase in mushroom poisonings [4]. According to our study, the highest number of publications was made in the last 3 years, with 2018 the most productive year with 239 documents. Similarly citations increased gradually, and the peak year was 2019 with 6034 citations. Markers of the popularity of this topic are the total of 62452 citations and 17.8 average citations per item.

We have seen that almost all regions of the world have produced publications related to mushroom poisoning, except some parts of Africa. We think this is evidence that mushroom poisoning is a global public health problem.

Findings of our study could help the experts in the fields of toxicology, intensive care and emergency medicine to identify the global research trends and patterns of mushroom toxicity and to offer a basis for future research directions.

Disclosures: There is no conflict of interest for all authors.

Acknowledgements: None.

Funding: None.

\section{References}

1. Durukan P, Yildiz M, Cevik Y, et al. Poisoning from wild mushrooms in Eastern Anatolia region: analyses of 5 years. Hum Exp Toxicol. 2007; 26:579-82. https://doi.org/10.1177/0960327106079545

2. Gonmori K, Yoshioka N. The examination of mushroom poisoning at Akita University. Legal Medicine. 2003; 5:83-6. https:// doi.org/10.1016/S1344-6223(02)00127-X

3. Peintner U, Schwarz S, Mešić A, et al. Mycophilic or mycophobic? Legislation and guidelines on wild mushroom commerce reveal different consumption behaviour in European countries. PLoS One. 2013; 8:e63926. https://doi.org/10.1371/journal. pone.0063926

4. Eren SH, Demirel Y, Ugurlu S, et al. Mushroom poisoning: retrospective analysis of 294 cases. Clinics. 2010; 65:491-6. https:// doi.org/10.1590/S1807-59322010000500006

5. Trestrail JH IIII. Mushroom poisoning in the United States: an analysis of 1989 United States Poison Center Data. J Toxicol Clin Toxicol. 1991;29:459-65. https://doi.org/10.3109/15563659109025741

6. Yardan T, Baydin A, Eden AO, et al. Wild mushroom poisonings in the Middle Black Sea region in Turkey: analyses of 6 years. Hum Exp Toxicol. 2010; 29:767-71. https://doi.org/10.1177/0960327110361758

7. Brayer AF, Froula L. Mushroom Poisoning. In: Tintinalli JE (edt) Emergency Medicine. 8th ed. McGraw-Hill Education. 2015; 1419-1424.

8. Unverir P, Soner BC, Dedeoglu E, et al. Renal and hepatic injury with elevated cardiac enzymes in Amanita phalloides poisoning: a case report. Hum Exp Toxicol. 2007; 26:757-61. https://doi.org/10.1177/0960327107083972

9. Karlson-Stiber C, Persson H. Cytotoxic fungi - an overview. Toxicon. 2003; 42:339-49. https://doi.org/10.1016/S00410101(03)00238-1

10. Jo WS, Hossain MA, Park SC. Toxicological profiles of poisonous, edible, and medicinal mushrooms. Mycobiology. 2014; 42:215-20. https://doi.org/10.5941/MYCO.2014.42.3.215

11. Colak S, Kandis H, Afacan MA, et al. Assessment of patients who presented to the emergency department with mushroom poisoning. Hum Exp Toxicol. 2015; 34:725-31. https://doi.org/10.1177/0960327114557902

12. Pajoumand A, Shadnia S, Efricheh H, et al. A retrospective study of mushroom poisoning in Iran. Hum Exp Toxicol. 2005; 24:609-13. https://doi.org/10.1191/0960327105ht572oa

13. Schenk-Jaeger KM, Rauber-Lüthy C, Bodmer M, et al. Mushroom poisoning: a study on circumstances of exposure and patterns of toxicity. Eur J Intern Med. 2012; 23 :e85-91. https://doi.org/10.1016/j.ejim.2012.03.014

14. Keller SA, Klukowska-Rötzler J, Schenk-Jaeger KM, et al. Mushroom Poisoning-A 17 Year Retrospective Study at a Level I University Emergency Department in Switzerland. Int J Environ Res Public Health. 2018; 15(12):2855. https://doi.org/10.3390/ ijerph 15122855

15. Şenel E, Demir E, Alkan RM. Bibliometric analysis on global Behçet disease publications during 1980-2014: is there a Silk Road in the literature? J Eur Acad Dermatology Venereol. 2017; 31:518-522. https://doi.org/10.1111/jdv.13897

16. Cervellin G, Comelli I, Rastelli G, et al. Epidemiology and clinics of mushroom poisoning in Northern Italy: A 21-year retrospective analysis. Hum Exp Toxicol. 2018; 37:697-703. https://doi.org/10.1177/0960327117730882

17. GunnMap. GunnMap 2. http://lert.co.nz/map/. Accessed January 12, 2018.

18. Vosviewer. VOSviewer - Visualizing scientific landscapes. http://www.vosviewer.com/. Published 2017. Accessed October 22, 2017.

19. UN. Country Classification. In: World Economic Situation and Prospects. New York. 2014:143-150. https://doi. org/10.18356/2a4ae6bb-en

20. Pritchard A. Statistical Bibliography or Bibliometrics? J Doc. 1969; 25(4):348-349.

21. Gawlikowski T, Romek M, Satora L. Edible mushroom-related poisoning: A study on circumstances of mushroom collection, transport, and storage. Hum Exp Toxicol. 2015; 34:718-24. https://doi.org/10.1177/0960327114557901

22. White J, Weinstein SA, De Haro L, et al. Mushroom poisoning: A proposed new clinical classification. Toxicon. 2019; 157:5365. https://doi.org/10.1016/j.toxicon.2018.11.007 